\title{
ENTRE O CAMPO E A CIDADE: FORMAÇÃO E REPRODUÇÃO SOCIAL DA CLASSE TRABALHADORA BRASILEIRA
}

\author{
ENTRE EL CAMPO Y LA CUIDAD: FORMACIÓN Y REPRODUCCIÓN \\ SOCIAL DE LA CLASE TRABAJADORA BRASILEÑA
}
BETWEEN COUNTRY AND CITY: FORMATION AND SOCIAL REPRODUCTION OF THE BRAZILIAN WORKING CLASS

\author{
Marta Inez Medeiros Marques \\ Profa. Dra. do Dep. de Geografia da Universidade de São Paulo \\ mimmar@usp.br
}

\begin{abstract}
Resumo
Este ensaio corresponde a um esforço inicial visando a compreensão dos processos de formação e reprodução social da classe trabalhadora no Brasil a partir da análise do avanço do processo de modernização e seus desdobramentos em sua relação com os espaços rural e urbano e formas de integração à modernidade.

Ele analisa importantes aspectos do modo de vida da classe trabalhadora brasileira, buscando identificar suas contradições para além das dicotomias moderno-tradicional, urbano-rural, camponês-proletário. Neste sentido, este ensaio é resultado de uma reflexão que visa superar uma compreensão reducionista do processo de modernização, que atribui poderes absolutos à tendência homogeneizante do desenvolvimento do capitalismo e prevê a subordinação de todo trabalho à forma trabalho assalariado, que é entendida como forma capitalista típica, e a urbanização completa da sociedade.
\end{abstract}

Palavras-chave: classe trabalhadora brasileira, relação cidade e campo, formação da classe trabalhadora, reprodução social, desenvolvimento geográfico desigual do capitalismo

\section{Resumen}

Este ensayo corresponde a un esfuerzo inicial que tiene como objetivo la comprensión de los procesos de formación y de reproducción social de la clase trabajadora en el Brasil, considerando el análisis del avance del proceso de modernización y de sus consecuencias en su relación con los espacios rurales y urbanos y las formas de integración a la modernidad.

El presente trabajo analiza aspectos importantes de la forma de vida de la clase trabajadora brasileña, buscando identificar sus contradicciones más allá de la dicotomía moderno-tradicional, urbano-rural e campesino-proletario. Así, este análisis se resulta de una reflexión elaborada con el objetivo de sobrepasar una comprensión reduccionista del proceso de modernización, que adjudica a la tendencia de homogeneización del desarrollo del capitalismo ilimitados poderes y prevé la subordinación de todo trabajo a la forma salariado, que se entiende como forma típica capitalista, y la urbanización completa de la sociedad. 
Palabras claves: clase trabajadora brasileña, relación cuidad y campo, formación de la clase trabajadora, reproducción social, desigual desarrollo geográfico del capitalismo.

\begin{abstract}
This essay corresponds to a preliminary effort to understand the process of formation and social reproduction of the working class in Brazil based on the analysis of the modernization process advancement and its consequences on its rural-urban relation and the forms of integration to modernity.

It analyzes important aspects of the way of life of the Brazilian working class, searching to identify its contradictions beyond the modern-traditional, urban-rural and peasantproletarian dichotomies. Thus, this essay results from a reflection that intends overcome a reductionist understanding of the modernization process, which attributes absolute powers to the trend of the capitalist development toward homogenization and foresees the subordination of all work to the form of wage labor, which is accepted as the typical capitalist form, and also foresees the total urbanization of the society.
\end{abstract}

Keywords: Brazilian working class, city-country relation, working class formation, social reproduction, uneven geographic development

\title{
Introdução
}

Este ensaio visa contribuir para a compreensão dos processos de formação e reprodução social da classe trabalhadora brasileira a partir da análise de importantes aspectos de sua relação com os espaços rural e urbano, suas formas de integração à sociedade moderna, bem como o modo de vida que lhes é característico. A teoria do desenvovimento geográfico desigual do capitalismo é aqui empregada como uma ferramenta fundamental para a interpretação dos processos e relações analisados, e apreensão do movimento geral que está na base da modernização desigual e contraditória que caracteriza a sociedade brasileira.

Ao estudar o sujeito social mobilizado na luta pela terra hoje no Brasil, depareime com a realidade de um trabalhador com complexa trajetória de vida, dividida entre o campo e a cidade. Tal fato deixou-me bastante intrigada e me instigou a buscar conhecer melhor a relação entre essa realidade e a história da classe trabalhadora brasileira em geral.

Assim, constatei que a condição de instabilidade que tem caracterizado historicamente a existência de muitos trabalhadores de baixa renda no país está relacionada nos últimos cinquenta anos a um intenso movimento entre o trabalho urbano 
e o rural, bem como à centralidade do papel desempenhado pela família e suas estratégias de reprodução social. O que me levou a refletir sobre a relação cidade-campo a partir da perspectiva da reprodução social da classe trabalhadora.

Em artigo publicado na Revista Terra Livre em 2002 (Marques, 2002), chamei a atenção para a necessidade de considerar a relação cidade-campo para compreender como se constituem os espaços rural e urbano, concebendo-os como constitutivos de uma totalidade dialética que os engloba. Totalidade que é determinada pelo capitalismo em seu movimento de reprodução ampliada, cuja unidade se forma na diversidade. De acordo tal concepção, esses dois espaços constituem meios criados a partir de uma multiplicidade de relações sociais de alcance diferenciado estabelecidas entre indivíduos, grupos sociais e entre estes e a natureza, que dão origem a configurações sociais específicas, conhecidas como ruralidade e urbanidade.

Enquanto a ruralidade tem se caracterizado tradicionalmente pela predominância de relações pessoais e de forte inscrição local, a urbanidade, ao contrário, é marcada pela alienação, separação, exterioridade e abstração. Na urbanidade, a lógica de mercado tende a englobar todas as esferas sociais, mediando a relação entre as pessoas e entre elas e a materialidade, fundando o sentido de universalidade a partir da abstração da forma mercadoria.

A urbanidade é a forma social típica da modernidade. Conforme Holanda (apud SEABRA, 2003:2), ela instaura um processo de complexificação social que comporta uma ordem impessoal e abstrata, desafiando a ordem doméstica e familiar da comunidade. Assim, a comunidade é recriada em geral em contextos sociais limitados e subordinados à ordem dominante que resulta da ação convergente do Estado e do mercado, como se pode geralmente observar a partir de uma análise da realidade em escala local.

A separação entre o econômico, o político e a vida imediata, que se constituem em diferentes esferas de significado, está na origem da constituição da urbanidade e tem gerado, com o desenvolvimento do capitalismo, a própria redefinição da ruralidade e resignificação da forma campo.

A seguir serão analisados alguns aspectos importantes relacionados à formação da classe trabalhadora no Brasil, que se dá com o avanço do processo de modernização, buscando identificar suas contradições para além das dicotomias moderno-tradicional, urbano-rural, camponês-proletário, bem como aspectos relacionados à sua reprodução social e ao seu modo de vida. Neste sentido, este ensaio é resultado de uma reflexão que 
visa superar uma compreensão reducionista do processo de modernização, que atribui poderes absolutos à tendência homogeneizante do desenvolvimento do capitalismo e prevê a subordinação de todo trabalho à forma trabalho assalariado, que é entendida como forma capitalista típica, e a urbanização completa da sociedade.

\section{Formação da classe trabalhadora, direitos e desigualdade social}

No século XIX, verifica-se a modernização da sociedade brasileira com o desenvolvimento de um mercado interno a partir de 1808, a estruturação do Estadonacional, a transformação da terra em mercadoria, a abolição da escravidão, a formação da classe trabalhadora etc.

A Lei de Terras de 1850 converte a terra em mercadoria e cria a possibilidade de o camponês se transformar em pequeno proprietário. Ao mesmo tempo em que essa a lei liberta a condição camponesa da estreita dependência da fazenda, subjuga o camponês a ela na medida em que será por meio de seu trabalho na fazenda que ele poderá vir a acumular recursos para comprar terra. Abre-se o caminho para um "novo" campesinato, cuja origem está relacionada com formas de trabalho híbridas (camponesas e não-camponesas como no caso do colonato) e cuja existência passa a ser mediatizada pela terra-mercadoria. Um campesinato moderno, cada vez mais dependente do mercado. (MARTINS, 1986:43)

Por outro lado, o final da escravidão também contribui para a redefinição das condições de vida do campesinato. A terra passa a ser o fundamento da dominação e exploração em lugar da relação de servidão e a disputa pela terra passa a opor camponeses e fazendeiros. Em 1891 as terras devolutas do patrimônio da União são transferidas para o patrimônio dos Estados e colocadas nas mãos das oligarquias regionais que delas se apropriam por meio de transferências maciças de propriedades. A especulação imobiliária e a necessidade de regularizar limites entre fazendas e de definir a situação jurídica da propriedade fundiária submetem terras camponesas à ameaça de incorporação ao patrimônio dos fazendeiros ${ }^{1}$. As primeiras grandes lutas camponesas no Brasil aconteceram entre o final do Império e começo da República (MARTINS, 1986:41-63).

\footnotetext{
${ }^{1}$ A processo de recadastramento georeferenciado das terras rurais em curso no país nos revela a persistência de uma situação de precária regularização do acesso à terra até os dias de hoje. Fato relacionado à manutenção da prática de incorporação de terras devolutas ao patrimônio privado por meios fraudulentos e aos conflitos de terra daí decorrentes.
} 
A vida urbana ganha maior dinamismo com o avanço da economia cafeeira e o crescimento do mercado interno, tornando a cidade gradativamente o lugar da produção. Contudo, a propriedade da terra não perde importância como fonte de riqueza e poder, e sendo firmados alianças e compromissos entre as elites agrárias e as elites urbanas em ascensão, muitas delas oriundas das oligarquias rurais.

O caráter rentista de nossas elites vem de longa data e é responsável pela manutenção da grande concentração de terras no campo e pelo processo de formação de periferias e segregação sócio-espacial que marca o nosso espaço urbano. O rentismo também está intimamente relacionado com os fundamentos de nossa extrema desigualdade social.

O início da industrialização e o deslocamento da base da economia do campo para a cidade verificados com base na acumulação de capitais gerada na economia cafeeira, dão origem a um efetivo mercado de trabalho. Este é caracterizado inicialmente pela forte presença de imigrantes de origem européia, sobretudo italianos.

Segundo Martins (1986), grande parte dessa mão-de-obra imigrante veio para o Brasil após ter sido vítima de expropriação e do processo de acumulação primitiva em seu país de origem, o que explicaria a centralidade apresentada pelo ideal de autonomia, característico do modo de vida camponês, na ideologia do trabalho desenvolvida no período, com repercussões na mentalidade do trabalhador contemporâneo. $O$ trabalho na fazenda ou na indústria é visto por muitos como o caminho para alcançar o retorno à terra e ao trabalho autônomo.

A abundante disponibilidade de mão-de-obra durante todo este período permitiu a manutenção dos salários em níveis baixos, favorecendo a expansão urbano-industrial. Além disso, o regime de salários deu origem a uma ampla camada social com capacidade de participar do mercado de bens de consumo corrente e criou novas oportunidades de investimento. (CANO, 1983:50)

A partir da década de 1920, a participação de migrantes nacionais passa a superar a entrada de imigrantes estrangeiros na composição da mão-de-obra empregada na cafeicultura e demais atividades do complexo cafeeiro. Estes migrantes, de origem predominantemente rural, também vão trazer hábitos e sonhos construídos em contextos sócio-espaciais distintos, no entanto, neste caso, eles são partes constitutivas de uma mesma formação sócio-territorial.

Queiroz (1978) identifica a adoção de um "estilo de vida burguês" nas grandes cidades desde o começo do século XIX, mesmo antes do início do processo de 
industrialização, que estaria na base da diferenciação entre a população urbana e a rural. A autora destaca ainda a diferença de ritmos e de tempos em que este processo se dá de uma região para outra, observando que, em regiões mais pobres, nas cidades menores, o modo de vida tenderia a se manter uniforme por mais tempo. Assim a maior dinâmica econômica de uma região estaria relacionada com a diversificação das funções urbanas e maior diferenciação e estratificação social.

A difusão do modo de vida citadino burguês determinaria mudanças na relação cidade e campo, com o aprofundamento de sua separação, opondo a "civilização citadina" à "civilização rústica". O prestígio do modo de vida da sociedade burguesa européia explicaria porque as pessoas que o adotam se consideram superiores à população do campo, mesmo quando esta pertença a níveis econômicos mais elevados. Nesse período, a separação entre cultura citadina e cultura rústica se superpõe grosseiramente à delimitação das fronteiras entre cultura erudita e cultura popular.

Queiroz (1978:60) defende que um modo de vida é um produto cultural e pode difundir-se fora da sociedade de que se originou desde que encontre condições adequadas para tal. Contudo, apesar de reconhecer que, sob determinadas circunstâncias, pode ocorrer a recriação de práticas e valores fora de seu meio original, não concordo que qualquer modo de vida seja capaz de alcançar difusão semelhante à apresentada pelo citadino burguês. O que sustenta a sua expansão é a sua íntima relação com as relações de mercado capitalistas e com a difusão do modo de ser e dos valores da sociedade moderna ocidental.

Souza (2000) defende que o processo de modernização iniciado no Brasil no século XIX institui o individualismo moral ocidental como código valorativo dominante, apesar de a nossa sociedade não se modernizar efetivamente em todas as esferas. Para o autor, a dominância desse código teria como conseqüência o fato de o discurso modernizador tornar-se o discurso legítimo, capaz de unir as vontades, mesmo diante da existência de outros códigos concorrentes.

A transição de uma cultura personalista para os valores impessoais da modernidade tende a se impor primeiro nas cidades no século XIX e depois no campo, no século XX. Souza (2000) lembra que, com ela, as oposições senhor/escravo, coronel/dependente tendem a ser substituídas por formas impessoais como doutor/analfabeto, trabalhador qualificado/trabalhador desqualificado. Nestas últimas, a relação independe de um vínculo de subordinação construído a partir de uma situação 
particular. A dominação torna-se impessoal e refere-se a valores inscritos no funcionamento das instituições modernas, especialmente aquelas do mercado capitalista.

A ascensão social torna-se supostamente possível para os indivíduos em geral, bem como o acesso à educação e a melhores oportunidades de emprego. A manutenção de amplos setores da população na condição de pobreza tende a ser vista como resultante do fracasso individual. A modernização seletiva se institucionaliza levando as elites tradicionais a aderirem à modernidade, abandonando os seus dependentes à sua própria sorte.

A crise da economia agroexportadora nos anos 1930 favoreceu o crescimento da produção industrial nacional por meio da substituição de importações. O Estado desempenhou importante papel neste período, ora atuando como produtor direto em setores básicos da produção com a criação de empresas estatais, ora atuando como agente regulador do mercado, inclusive do mercado de trabalho.

A constituição de 1934 define uma legislação trabalhista para o país - salário mínimo, descanso semanal e férias remuneradas, 8 horas de trabalho diário, previdência social $^{2}$. Nesta ocasião, a inserção no mundo do trabalho formal passou a representar o principal meio de acesso à cidadania.

$\mathrm{Na}$ medida em que a legislação trabalhista não se estende ao campo, a cidade a ele se opõe como o espaço da cidadania. Migrar para a cidade passa a representar, então, uma maneira de ampliação das possibilidades de entrar no mundo do direito. Institucionaliza-se uma cidadania excludente.

Durante o Estado Novo (1937-45) a sociedade industrial e urbana se consolida com a diversificação da produção e ampliação do mercado interno. Dada a restrição da industrialização à produção de bens de consumo leves, parte significativa da mão-deobra disponível não é absorvida pelos setores ditos modernos da economia, nos quais o trabalhador tinha os seus direitos reconhecidos. Sobretudo a mão-de-obra de menor qualificação, mantém-se subempregada em serviços domésticos, comércio ambulante, biscates etc.

No entanto, como afirma Telles (1994:93), no Brasil, “a lei, ao invés de garantir e universalizar direitos, destitui indivíduos de suas prerrogativas de cidadania e produz a

\footnotetext{
${ }^{2}$ A Consolidação das Leis do Trabalho de 1943 reúne toda a legislação social e trabalhista criada no período e até hoje constitui a principal referência para a regulamentação das relações entre patrões e empregados no país.
} 
fratura entre a figura civil do trabalhador e a do pobre incivil." A experiência da falta de direitos se reflete na sociabilidade, identidade e modos de existência.

O crescimento das cidades e o esvaziamento demográfico do campo se dão com o confinamento de massas despossuídas em grandes bolsões de pobreza. O grau de indigência é tal que, os parcos recursos a elas destinados pelo Estado conferem a este um grande capital político. Verifica-se, contraditoriamente, a disseminação de formas de clientelismo urbano.

A agricultura atravessou dificuldades neste período, principalmente nos Estados do Norte, Nordeste, e de Minas Gerais, gerando o empobrecimento do campo. O messianismo e o banditismo surgem como formas dominantes de manifestação da rebeldia camponesa. As ligas camponesas e os sindicatos vão ocupar o cenário somente a partir dos anos 1950 (MARTINS, 1981:67).

A agricultura recupera-se em São Paulo e, juntamente com a indústria, atrai mão-de-obra de outras regiões, sobretudo de origem rural. A grande oferta de trabalho pressiona os salários para baixo, gerando grande insatisfação entre os trabalhadores e contribuindo para o avanço da organização sindical e do movimento operário.

Em 1964 ocorre o golpe militar e o endurecimento do Estado em face dos movimentos sociais urbanos e rurais. Trata-se de uma fase de expansão do capitalismo monopolista, das multinacionais, que contou com o apoio de um governo forte para conter a base trabalhadora. Enquanto isso, nos países centrais os trabalhadores alcançavam importantes conquistas políticas, sociais e salariais.

A consolidação do capitalismo monopolista no país resultou na diversificação de nosso parque industrial e numa maior diferenciação social interna à classe trabalhadora. Forma-se uma classe média constituída por trabalhadores mais bem remunerados, comumente vinculados às grandes empresas.

O projeto desenvolvimentista implementado pelos governos militares foi responsável pela realização de grandes obras de infra-estrutura como a construção de estradas e de usinas hidrelétricas, desencadeando fortes impactos sociais e ambientais. Também executou um conjunto de políticas visando à modernização da base técnica na agricultura e a consolidação de complexos agroindustriais.

A industrialização da agricultura gera mudanças nas relações de produção, com a crescente substituição da mão-de-obra camponesa residente na fazenda pelo trabalhador vindo de fora, contratado em caráter temporário. Surgem os bóias-frias, que expressam o resultado do avanço do processo de proletarização no campo. 
No final dos anos 1970, observa-se a reorganização dos trabalhadores e o fortalecimento dos sindicatos, com forte participação de sua camada média. O momento de redemocratização do país abriga o crescimento das lutas e mobilizações sociais em geral, seja no campo ou na cidade.

Porém, as baixas taxas de crescimento econômico, verificadas a partir de 1980, causam o enrijecimento da estrutura social no país, reduzindo as oportunidades de ascensão social. Tal fato alia-se ao aumento da desigualdade social, dos bolsões de pobreza e da violência e da criminalidade urbanas, o que gera o agravamento da questão social.

Os anos 90 inauguram o processo de abertura do mercado interno às importações, causando a desindustrialização de grandes centros urbanos, o que, aliada à revolução informática, vem produzindo a eliminação de postos de trabalho. Porém, como lembra Nascimento (1996), déficits habitacionais e de serviços sociais, e uma estrutura fundiária extremamente concentrada, representam um amplo potencial para a criação de novos empregos no Brasil. É a rigidez da estrutura de poder que tem bloqueado a utilização deste potencial.

Prevalece a tendência de aumento do desemprego e uma crescente precarização das relações de trabalho, com o crescimento do setor informal, abrigando um número significativo de trabalhadores temporários e subempregados. O nomandismo ocupacional, que tem cada vez mais caracterizado a condição de nosso trabalhador, representa uma relação descontínua com o trabalho. Em todo momento, o mercado desfaz a trama por onde identidades se completam (TELLES, 1994).

Por outro lado, são inúmeras as clivagens de qualificação e salário, produzidas por um processo que diferencia e hierarquiza a força de trabalho sob critérios muitas vezes arbitrários.

No entanto, na ausência de uma medida possível de equivalência entre situações diversas, medida esta que só poderia ser dada pelos direitos (medida, portanto, que só poderia existir por referência aos valores de justiça e igualdade), desigualdades e discriminações se pulverizam em diferenciações que parecem corresponder nada mais que aos azares de cada um e às diferenças de vocação, talento, capacidade e disposição para o trabalho (TELLES, 1994:98).

Ao longo das últimas cinco décadas, a pobreza deslocou-se do campo para a cidade, concentrando-se nas metrópoles e tornando-se mais visível. Observa-se, nestes 
centros urbanos, um forte aumento da violência e do desemprego, além de precárias condições de acesso à saúde, educação e habitação, com grande parte da população morando em cortiços, favelas e periferias.

A ação da mídia, sobretudo da televisão, também tem contribuído para uma maior visibilidade da pobreza, que aparece associada à violência. Mas a violência urbana não é resultado direto da pobreza, ela está relacionada, entre outros fatores, à contradição resultante da maior visibilidade das desigualdades sociais e à pressão que os meios de comunicação exercem no sentido de homogeneização simbólica das aspirações e dos modos de vida.

Camargo (1990) fala da "entrada na modernidade pela contramão", ou seja, pela acelerada expansão da mídia divulgando bens e valores de uma sociedade individualista de afluência, junto a uma massa carente que vive em condições de subcidadania.

Também contribuem para o aumento da violência a falta de perspectivas das camadas pobres e a uma crise de sociabilidade que se dá pelo afrouxamento dos grupos primários que asseguram o controle social; pela crise de valores, moral e ética e pela crise de legitimidade das instituições. $\mathrm{O}$ avanço da modernidade capitalista debilitou um conjunto de instituições, gerando uma mistura contraditória entre elementos do tradicionalismo e da modernidade na qual, ora prevalecem arranjos pessoais ou corporativos, ora predominam as impessoais leis de mercado, desvinculadas de certos valores morais e éticos partilhados pela sociedade.

O campo tradicionalmente tem abrigado um importante segmento da população sobrante no Brasil. Verifica-se uma tendência de acúmulo de desempregados disfarçados no âmbito da produção familiar e de trabalhadores sem-terra e sem função econômica nas vilas e pequenas cidades, fato que está intimamente relacionado com o aumento das tensões sociais neste espaços.

Com o agravamento dos problemas sociais nas grandes cidades, verifica-se o arrefecimento da migração rural-urbana e inter-regional, gerando um crescimento surpreendente em áreas rurais e pequenas localidades (MARTINE, 1995). Entre 1990 e 1993, mais de $91 \%$ das pessoas que se somaram ao total de ocupados se dirigiram à agricultura (SINGER, 1996). No entanto este setor de atividades não apresentou expansão no período. A maioria desses novos ocupados vinculou-se à produção familiar, conhecido refúgio de trabalhadores afetados pelo desemprego.

A mobilidade espacial, historicamente relacionada com a perspectiva de mobilidade social atravessa uma nova fase. A redistribuição espacial de nossa 
população, que, de modo geral, acompanhou a evolução do mercado de trabalho, tem obedecido a outros padrões nos últimos anos. As grandes cidades reduziram seu ritmo de crescimento devido à redução brutal das oportunidades de emprego nestas cidades. Por outro lado, são estabelecidos fluxos de retorno de regiões mais ricas para regiões mais pobres.

Entre outros fatores que explicam este processo, não se pode esquecer a cultura de sobrevivência, que, em momentos de crise aguda, impõe a opção pelo lugar mais conhecido, onde se conta com uma rede de relações já estabelecida. A maior visibilidade da pobreza urbana provavelmente também afeta o êxodo rural. A hipótese é a de que ela reforçaria a sensação de falta de perspectivas e estimularia o retorno ou a permanência no local de origem.

Por outro lado, alguns municípios de maior atração migratória, localizados nas regiões Sudeste e Sul passam a adotar posturas agressivas em relação à entrada de migrantes em seu território. Ocorre o fechamento do território urbano a migrantes nessas áreas. São políticas territoriais ativas voltadas para a segregação sócio-espacial (VAINER, 1995).

Outrora a cidade correspondia ao mundo do direito e era em relação a este que se construía a identidade do trabalhador, opondo-se à do pobre incivil. Com a precarização dos vínculos de trabalho esta referência é enfraquecida e a identidade do trabalhador passa a opor-se à do bandido. "Entrar" na terra, neste caso, pode representar, para muitos que se encontram em situações de extrema precariedade, a recuperação da dignidade da condição de trabalhador e a possibilidade de se realizar um projeto de reprodução da família longe da violência urbana.

A unidade familiar camponesa continua a representar parcela significativa da população trabalhadora no campo e a abrigar desempregados rurais e urbanos. Além disso, tem sido palco de inúmeras mudanças de caráter social, econômico, político e cultural, decorrentes de sua maior aproximação do mundo urbano.

A presença de trabalhadores de origem urbana nos movimentos de luta pela terra no Brasil hoje constitui mais um elemento a nos indicar o quão imbricadas são as trajetórias tecidas por nossos trabalhadores entre o campo e a cidade e o quão complexo é o processo de proletarização em curso. 


\section{A reprodução social dos trabalhadores pobres e seu modo de vida}

Diante de todos estes fatos, a análise sobre como tem se reproduzido a classe trabalhadora brasileira apresenta grande relevância.

$\mathrm{Na}$ tradição marxista, as teorias sobre a reprodução social enfatizam a prática e a autonomia relativa das diferentes esferas da vida cotidiana e apresentam interesse em questões de ideologia ou hegemonia e nas formas de contestação das mesmas (MITCHELL et al., 2003:424).

Os processos de constituição do trabalhador e de reprodução da classe trabalhadora são processos históricos múltiplos, envolvendo relações de poder entre diferentes grupos sociais, além da separação do trabalhador dos meios de produção, o que vem a exacerbar tais relações de força (MITCHELL et al., 2003:427).

É preciso compreender como os espaços são criados, recriados e alterados pelos sujeitos cujas práticas cotidianas os constituem e como a hegemonia se sustenta nestes espaços superpostos para os quais convergem casa e trabalho, público e privado, Estado e sociedade (MITCHELL et al., 2003:433).

Conforme lembram Mitchell et al. (2003:420), as análises de Marx sobre reprodução das relações sociais capitalistas geralmente consideram apenas o trabalho assalariado, ignorando as variadas formas de trabalho não contratado ou não remunerado com base numa troca monetária. São exemplos de trabalho não assalariado, o trabalho doméstico, o trabalho camponês, os trabalhos envolvidos em economias subterrâneas etc.

Mitchell et al. (2003) defendem que o trabalho reprodutivo é um processo tão fundante para o capitalismo e para a subjetividade capitalista quanto é o trabalho assalariado. A constituição do indivíduo como um "trabalhador" engajado em trabalho assalariado ou não-assalariado ou ambos é um produto dos espaços heterogêneos e práticas desiguais de desenvolvimento capitalista e também dos muitos outros processos estruturantes parciais e desiguais associados com a vida material (MITCHELL et al., 2003:422).

A reprodução social da classe trabalhadora está relacionada à reprodução biológica da força de trabalho, em bases cotidianas e através de gerações, por meio da aquisição e distribuição dos meios de existência incluindo comida, abrigo, vestimenta e cuidados com a saúde (KATZ, 2001:711). A reprodução social diz respeito a como nós 
vivemos no e fora do trabalho e é constituída pela confusa e, muitas vezes, indeterminada matéria da vida cotidiana.

Neste sentido, destaca-se a importância da família como unidade social que agrega membros com e sem renda, práticas solidárias de vizinhança e atividades de auto-subsistência como o plantio de hortas e a criação de pequenos animais em fundos de quintal. Aliada a estas estratégias também se observa a articulação entre a reprodução de parte da família no campo e parte na cidade, com fluxo de renda e de pessoas nas duas direções.

Os trabalhadores empobrecidos do campo e da cidade correspondem a categorias sociais que ocupam diferentes posições em relação ao processo de produção material. Porém, uma série de fatores contribui para o surgimento de identificações e alianças entre elas, tornando, muitas vezes, difícil uma distinção nítida entre os representantes de um e outro grupo.

A origem rural de grande parte dos trabalhadores da cidade é um dos fatores que explica as identificações que estes possuem com os trabalhadores rurais. Por um lado, muitos deles se mantêm ligados à área de procedência por meio de vínculos familiares, sendo possível o seu retorno em momentos de crise, sobretudo quando a família possui um pedaço de terra. Por outro, observa-se que valores e tradições do modo de vida anterior são reinterpretados e recriados no contexto urbano, refletindo-se, de diferentes formas, nas práticas e estratégias por eles adotadas em seu dia-a-dia.

$\mathrm{Na}$ cidade, o trabalhador pode passar da condição de operário para a de autônomo, desempregado ou inativo e uma mesma família pode possuir membros correspondentes a várias categorias. Com exceção de um segmento mais qualificado, uma ampla maioria de trabalhadores tem a sua trajetória marcada pela insegurança, instabilidade e precariedade dos vínculos com o trabalho. A alta rotatividade no emprego e a frequente mudança de ocupação, somadas à baixa remuneração e à assistência estatal limitada e ineficiente, tornam os trabalhadores pobres dependentes de uma rede de relações desenvolvida no local de moradia com base em laços de parentesco, vizinhança e procedência. Esta rede de relações é mais estável e significativa que as relações impessoais que eles estabelecem com a sociedade envolvente, seja no mundo do trabalho, seja através de instituições de serviços urbanos ou organismos públicos.

Os trabalhadores empobrecidos do campo e da cidade partilham uma situação semelhante em muitos aspectos. Ambos os segmentos, apesar de integrados à estrutura 
social dominante, em geral não usufruem a sua face "civilizadora", pois, se encontram à margem da ação protetora do Estado e do "mundo dos direitos", bem como à margem do acesso à escolarização e às comodidades da vida moderna. Assim, as categorias e valores da lógica tradicional tendem a se tornar importantes referências na visão de mundo desses trabalhadores devido à sua trajetória e também porque se opõem à dominação da ideologia moderna.

A relativa similaridade das múltiplas práticas cotidianas dos habitantes de favelas ou bairros pobres da periferia das cidades e a troca de experiências realizada entre eles é a base a partir da qual se desenvolve uma cultura popular. A cultura dos pobres na cidade e a cultura camponesa representam manifestações específicas da cultura popular, que, por sua vez, apresenta-se inserida no contexto da dinâmica cultural brasileira. A utilização do termo popular visa realçar os elementos culturais comuns que podem ser encontrados nos diferentes modos de vida engendrados pelas classes subalternas em nossa sociedade.

A cultura não é aqui compreendida como uma forma social fixa e cristalizada, mas como um produto social resultante das estratégias desenvolvidas nos diversos campos de lutas por uma determinada classe ou grupo social em seu processo de reprodução social. Assim, a cultura popular expressa os embates relativos ao processo de dominação, bem como a posição política assumida pelas classes subalternas nos diferentes momentos da história, oscilando entre conformismo e mobilização e resistência. 


\section{Considerações finais}

A subordinação do campo aos interesses de classe sediados na cidade está relacionada à posição que camponeses e trabalhadores rurais ocupam na sociedade, à função que desempenham na divisão social do trabalho e ao lugar que lhes é reservado como espaço de vida. Da mesma forma, a constituição de periferias urbanas reflete a posição ocupada pela classe trabalhadora e sua reprodução social no quadro geral de reprodução da sociedade capitalista e das relações de poder dominantes no Brasil. A configuração desses lugares é influenciada por múltiplas relações, incluindo aquelas estabelecidas para além das fronteiras locais, seja no nível da ordem do mercado, ordem distante, seja no nível da ordem próxima, em que são comumente mantidos vínculos e solidariedades entre os trabalhadores da cidade e do campo como estratégia de reprodução social.

$\mathrm{Na}$ fase atual do capitalismo, marcada pela mobilidade e complexidade social crescente, o trabalho enfrenta um momento crítico, desafiando formas consagradas de comprensão do capitalismo baseadas numa perspectiva evolucionista. À instabilidade que historicamente marcou a trajetória da classe trabalhadora no Brasil e que com freqüência foi interpretada como expressão de nosso atraso sócio-econômico, soma-se a tendência mundial de institucionalização de relações de trabalho de caráter "transitório" e "externalização" dos custos de reprodução da força de trabalho pelos capitalistas, o que pode se manifestar como formas de "flexibilização" e precarização do trabalho.

O real significado e dimensão dessa nova realidade estão ainda por ser decifrados. Porém, para superar os limites de uma abordagem estrutural-evolucionista, é preciso: (1) aprofundar o nosso conhecimento sobre o processo de reprodução social da classe trabalhadora e suas formas de espacialização que têm lugar entre o campo e a cidade; e (2) analisar as novas/velhas formas de trabalho existentes, assalariadas e nãoassalariadas, e sua relação com o desenvolvimento geográfico desigual do capitalismo. Tal empreendimento exige um esforço no sentido da construção de uma teoria capaz de relacionar os processos que se desenvolvem em diferentes escalas espaço-temporais, do local ao global. A dinâmica social hoje impõe a necessidade de compreensão dos processos que se desenvolvem em diferentes escalas e suas interrelações. Esse é o desafio que temos pela frente. 


\section{Referências}

CAMARGO, Aspásia. As duas faces de janus: os paradoxos da modernidade incompleta. In: J. P. dos R. Velloso (coord.), A crise brasileira e a modernização da sociedade. Rio de Janeiro, José Olympio, 1990.

CANO, Wilson. Raízes da concentração industrial em São Paulo. 2 ed., São Paulo, T. A. Queiroz, 1983.

KATZ, Cindi. Vagabond capitalism and the necessity of social reproduction. Antipode, 33(4):709-728, 2001.

MARQUES, Marta Inez M. O conceito de espaço rural em questão. Revista Terra Livre, São Paulo, 18(19):95-112, jul/dez de 2002.

MARTINE, George. A evolução espacial da população brasileira. In: R. de B. A. Affonso e P. L. Barros Silva (orgs.), Desigualdades regionais e desenvolvimento. São Paulo, FUNDAP: UNESP, 1995.

MARTINS, José de S. Os camponeses e a política no Brasil. Petrópolis, Vozes, 1981. . O cativeiro da terra. 3ed., São Paulo, HUCITEC, 1986.

MITCHELL et al., Introduction: Life's Work: an introduction, review and critique. Antipode, 35(3):415-442, 2003.

NASCIMENTO, Elimar P. Novos personagens do espaço urbano brasileiro: a respeito dos efeitos da desigualdade social. Brasília, UNB, 1996. (mimeo.)

QUEIROZ, Maria Isaura P de. Cultura, sociedade rural, sociedade urbana no Brasil. Rio de Janeiro/São Paulo, LCT/EDUSP, 1978.

SEABRA, Odete. Urbanização e fragmentação: cotidiano e vida de bairro na metamorfose da cidade em metrópole, a partir das transformações do bairro do Limão. São Paulo: Faculdade de Filosofia, Letras e Ciências Humanas da Universidade de São Paulo, 2003. (Tese, Livre Docência).

SOUZA, Jessé de. A modernização seletiva. Brasília, EdUnB, 2000.

SINGER, Paul. Dimensões da crise econômica. Folha de São Paulo, São Paulo, 2 de junho de 1996. Dinheiro, Caderno 2, p.2.

TELLES, Vera da S. Pobreza e cidadania: precariedade e condições de vida. In: H. H. de S. Martins e J. R. Ramalho (orgs.), Terceirização: diversidade e negociação no mundo do trabalho. São Paulo, HUCITEC: CEDI/NETS, 1994.

VAINER, Carlos B. Regionalismos: anacronismo ou pós-modernidade?. In: M. F. Gonçalves (org.), O novo Brasil urbano: impasses, dilemas, perspectivas. Porto Alegre, Mercado Aberto, 1995. 